\title{
Risk Factors Affecting Condom Use among Royal Thai Army Conscripts in Thailand
}

\author{
Phrutthinun Surit ${ }^{1,2}$, Wutthichai Jariya ${ }^{3}$, Ning Zheng ${ }^{4}, \mathrm{He} \mathrm{Yi}^{4}$, Xiaojing $\mathrm{Yu}^{4}$, \\ Watcharee Srithong ${ }^{3}$, Saisiri Mirasena ${ }^{1,2^{*}}$ \\ ${ }^{1}$ Faculty of Medical Science, Naresuan University, Phitsanulok, Thailand \\ ${ }^{2}$ Center of Excellence in Medical Biotechnology (CEMB), Naresuan University, Phitsanulok, Thailand \\ ${ }^{3}$ Faculty of Public Health, Naresuan University, Phitsanulok, Thailand \\ ${ }^{4}$ Shanghai Municipal Center for Disease Control \& Prevention, Shanghai, China \\ Email: *saisirim@gmail.com
}

How to cite this paper: Surit, P., Jariya, W., Zheng, N., Yi, H., Yu, X.J., Srithong, W. and Mirasena, S. (2017) Risk Factors Affecting Condom Use among Royal Thai Army Conscripts in Thailand. World Journal of $A I D S, 7,92-105$.

https://doi.org/10.4236/wja.2017.72009

Received: November 28, 2016

Accepted: June 13, 2017

Published: June 16, 2017

Copyright (C) 2017 by authors and Scientific Research Publishing Inc. This work is licensed under the Creative Commons Attribution International License (CC BY 4.0).

http://creativecommons.org/licenses/by/4.0/

\begin{abstract}
The study was conducted to explore factors associated with condom use of young Thai men conscripts. Methods: A cross-sectional study was conducted. Participants were 159 conscripts in second year who served in the Royal Thai Army by lottery method. Demographic data, sexual history including condom use, HIV and STDs and knowledge were collected using a self-administered questionnaire. Logistic regression was used to analyze the data. Results: Condom use at the last sex was $41.18 \%$ of the conscripts aged $20-27$ years and secondary school education completed of $74.2 \% .25 .78 \%$ had experience with drugs used but injection was rare (6.9\%). Age at the first sex was reported lowest at 11 years, 9.4\% reported first sex with men and $21.38 \%$ were married. The participants have sexual history (last six months) with female only of $83.2 \%$, male only of $4.1 \%$ and both of $14.6 \%$. Among these only $12.6 \%$ reported every time of condom use and $19.5 \%$ never used condom. Older age, higher education, drinking alcohol, drugs use and higher knowledge were associated with condom use with statistical significance. Conclusions: Condom use among male Thai conscripts was low. Education and a condom use program are urgently needed to prevent future spread of HIV and STDs.
\end{abstract}

\section{Keywords}

Conscript, Condom, AIDs, Sexually Transmitted Diseases, Thailand

\section{Background and Rationale}

Military personnel have a high risk of exposure to sexually transmitted diseases, including HIV. Sexual Transmitted Diseases (STDs) infection rates among armed forces are generally 2 to 5 times higher than in comparable civilian popu- 
lations [1]. The difference can be even greater in times of conflict. Studies in the USA, the UK, and France show that soldiers from these countries have a much higher risk of HIV infection than equivalent age/sex groups in the civilian population [2]. Recent figures from Zimbabwe and Cameroon show military HIV infection rates 3 to 4 times higher than in the civilian population [3]. Conscript personnel are a population group at special risk of exposure to STDs, including HIV [4]. Conscripts are almost all young people, who are in the stage of adolescence when the individual develops physically and emotionally, becomes sexually active and adopts behaviors that are influenced by psychological aspects related to this age group [5]. They frequently have a high-risk behavior pattern which includes inconsistent condom use, sexual activity with multiple partners and the use of alcohol or drugs before having sexual intercourse [6] and are likely to be exposed to illicit drugs, alcohol and cigarettes, Moreover, they have risk-taking sexual behavior such as having sex with commercial sex-workers (CSW) and some persons have sex with men or are men who have sex with men (MSM) [7] [8].

The fact that in the military there are men who have sex with men is a sensitive issue in many countries [1]. Some sexual contacts occur between men who identify themselves as homosexual or bisexual. In some cases there is coerced sex (rape) among men. Finally, men who identify themselves as heterosexual may experiment with male-to-male sexual activity (for example, during periods of isolation from female companionship) [2] [7] [9]. Little research has been done on this, but recent studies suggest that such activity may be more widespread than isgenerally assumed [1] [8].

The first case of HIV/AIDS in Thailand was reported in1984 in a bisexual man returning from abroad [10]. However, it was suspected that HIV/AIDS had been in the country for four-to-five years before that [11]. In response to the epidemic, the Ministry of Public Health (MoPH) had included AIDS in the list of modifiable communicable diseases since 1985, requiring reports of cases when detected. This requirement was dropped in 1991 and replaced by sentinel surveillance activities, which have been in place since June 1989 [2] [11]. The sentinel surveillance was initially started twice a year in a few provinces and then expanded nationwide in 1991; it has been reduced to once a year since June 1995 [2]. Moreover, the Thai government and its partners rapidly implemented pragmatic HIV prevention programs, including the campaign for $100 \%$ condom use in sex-workers [12]. Subsequently, from 1989 to 2006, the HIV prevalence fell from $33.2 \%$ to $4.6 \%$ in female sex-workers, from $2.3 \%$ to $0.9 \%$ in pregnant women, and from $4.0 \%$ to $0.5 \%$ in young military recruits [13]. Despite the success in reducing HIV infection, little information is available about MSM in the Thai HIV epidemic [14].

According to the report on sentinel surveillance of HIV infection in the seven major target groups of population in Thailand, implemented in all provinces during the period 1989-2009, included were blood donors, pregnant woman, injection drug users, male clients attending STIs clinic, direct female commercial 
sex-workers (CSWs), indirect female CSWs and military recruits or conscripts. The AIDS division of the Ministry of Public Health (MoPH) reported that the HIV prevalence among military conscripts in Thailand has been nearly thesame percentage since 2001. In 2006 the prevalence was $0.9 \%$ in Bangkok and 0.5\% in the countryside [11] [14]. While the previous study found that the prevalence increased from 1.6\% in 1990 to the peak of $4 \%$ in 1993, since then it has dropped to $0.5 \%$ in 2009 , and the trend seems to be increasing in recent years [11].

Recruitment of Thai males for military service (mostly 21-year-olds) occurs in April every year. Placement takes place twice a year in May and November. Since November 1989, the Army Institute of Pathology, King Mongkut Medical Center and the Royal Thai Army (RTA) Medical Department, in cooperation with 37 military hospitals, have conducted HIV screening among RTA conscripts in order to assess the prevalence of HIV infection among this group of Thai men. Demographic data have been additionally collected since 1991. Data from this measure are useful in planning of the RTA reserve, workforce administration, and the arrangement of counseling services to improve the quality of life of affected persons [2] [11].

In Thailand, it was found that the HIV/AIDS epidemic among the recruitment conscripts in the North was the most critical. In 1993, national HIV prevalence was found to be as high as 7.4\% [11]. The situation improved after all concerned sectors undertook HIV prevention and control campaigns. At the same time, HIV prevalence in most regions was gradually declining and the national prevalence fell to $0.7 \%$ in 2002 . As of early 2002 , the highest prevalence of $1 \%$ was observed in the South [11]. Therefore, it can be seen that, starting in 2001, there were sustained declines of HIV in each region, especially in the upper north and central regions. However, it is noteworthy that, in the past five years, these declines have reached a plateau with a slight increasing trend since 2007. In 2009, the prevalence of HIV among the recruits was highest in Bangkok (0.6\%); in the other regions HIV increased from 0.4 to 0.5 in 2008 and 2009 respectively. Data which confirm the worrisome levels and trends of HIV come from STI data in military recruits in the second round of the draft in 2008. At that time, the prevalence of non-specific urethritis was $6.86 \%$, gonorrhea $0.86 \%$ and syphilis $0.09 \%$. The level of infection was highest in the upper north and east (part of the central region) in which the rates were $13.1 \%$ and $12.5 \%$ respectively [11] [15].

Surveillance of sexually transmitted infections (STIs) among RTA conscripts-found that this rate decreased from 150 per 100,000 in 1993 to fewer than 10 per 100,000 since 1997. In a survey of the knowledge, attitudes and preventive practices among RTA personnel, it was found that over $70 \%$ had been informed about HIV/AIDS from the RTA medical officers. More than $75 \%$ had accurate knowledge about HIV/AIDS and more than 55\% consistently used condoms in extra-marital sexual relations. Despite the early absence of MSMspecific studies, research on HIV risk-behavior in young Thai men showed homosexual activity to be common among military conscripts, students, and fac- 
tory workers. In these studies the prevalence of male-to-male sex ranged from $3.3 \%$ to $16.3 \%$ [16] and inconsistent condom use with men from $52.8 \%$ to $60.0 \%$ [17]. The data also confirmed the decrease in condom use in Bangkok, where the percentage of consistent condom use among RTA conscripts when having sex with sex-workers increased significantly from $26 \%$ in 1991 to more than $80 \%$ in 2001 and dropped to $60 \%$ in 2006 . This percentage continues to decrease [18]. Therefore, it is necessary to conduct research among Thai conscripts to study the prevalence of condom use among RTA personnel and their sexual risk-behavior and identify the factors associated with the sexual risk-behavior. This study also examined the sexual knowledge, attitudes and sex behaviors of young men conscripted to serve in the military. This information may help in developing appropriate HIV prevention interventions for distinct populations of people in Thailand and elsewhere.

\section{Material and Methods}

\subsection{Study Design}

This study was performed by cross-sectional study with one selected location, as defined by the mapping of ART regions, in Naresuan-Troop, Phisanulok Province, Thailand. This study was approved by Naresuan University, the Royal Thai Army, the Ministry of Public Health, Thailand and the Shanghai Municipal Centre for Disease Control and Prevention, Shanghai, P. R. China

\subsection{Settings and Participants}

Recruitment of Thai males (mostly 21-year-olds) for conscript service to RMT/ RTA occurs in April every year by lottery method. Placement takes place twice a year in May and November, and there is a two-year period of service in the Thai army. The participants were the conscripts into the military and the study was performed as a sampling plan by two stages selection stratifying. In the first stage, the selection commissions were stratified by geographical macro RTA region and selected with probability proportional to size, which was defined by the frequency of conscripts presented in the previous year (2015). In the second stage, conscripts were selected at the moment of their presentation, in a number proportional to the size of the selection commission. The sample size was confirmed by two location sampling with $95 \%$ confident interval $(95 \% \mathrm{CI})$ and the anticipated relative precision of $30 \%$ HIV prevalence [18] with the power of $80 \%$.

\subsection{Measurement}

The self-administered questionnaire was developed based on a literature review. The questionnaire which was initially written in English format and then translated into Thai, consisted of background characteristics, sexual history, HIV and STDs, knowledge, practice, and attitudes towards HIV/AIDs and STDs and other ideas, suggestions or recommendations. The variables included in this paper were selected from among these questions. After permission from the RTA, 
all conscripts in year 2 were selected and were asked to fill out the self-administered questionnaire. The staffs were trained to distribute and collect the questionnaire. All conscripts were informed of the study's purposes and invited to participate in the study, then were asked to sign the consent form. The participants were also told that the survey was anonymous and the data was presented only in an aggregate manner, so that the participants' privacy and confidentially would be protected.

\subsection{Statistical Analysis}

The measurement of condom use was defined as "yes" or "no" for the last sexual intercourse in the last six months. In addition to the knowledge and attitude variables, this study created abinary scale ("yes" or "no" scale) for statistical analysis. Participants were categorized into low and high score groups based on the distribution of the total score in each scale. The data was analyzed using computer program, and the descriptive statistics including percentage, mean, standard deviation and median was performed to identify characteristics of the participants. Logistic regression was used to determine the odds of selected sexual risk-behavior. Analysis was to adjust for the potential effect of variables.

\section{Results}

The/A total of 159 conscripts aged 20 - 27 years $($ mean $=21.01)$ was employed in this study. The majority of the respondents completed secondary education (74.2\%) and had income of 5000 - 10,000 Baht per month. More than half never drank alcohol (60.4\%) while, 22.5\% reported drinking once a week. More than one-fourth of the respondents used to take drugs/used drugs (25.8\%) and 6.9\% reported injection of drugs. Moreover, more than three-fourths were unmarried and the youngest were married at 15 years (Table 1).

\subsection{Sex History}

Among respondents, $90.6 \%$ experienced first sex with a female and $9.3 \%$ had first sex with a male and the youngest age at the first sex of 11 years and the oldest of 20 years $($ mean $=15.8)$. Meanwhile, nearly half of the respondents were unmarried and living alone (44.7\%) and 33.9\% living with a sex partner. For sexual intercourse in the past six months, the majority of the respondents had sexual intercourse with only female (83.2\%), $14.8 \%$ had sexual intercourse with both female and male, while $4.0 \%$ had sex with only male. For sex with female, the respondents reported the highest of 15 sex partners, $41.8 \%$ used a condom for the last sexual intercourse, and among these $65.1 \%$ of the respondents offered to use a condom, while $9.5 \%$ were requested to by a sex partner. Nevertheless, the respondents showed that the reasons for not using a condom were: didn't like it, didn't think of it, not available and didn't think it was necessary (64.4\%, 62.2\%, 35.6\% and 30.00\%, respectively). For the frequency of condom use, a half of the conscripts reported condom use sometimes (50.3\%), $17.6 \%$ reported almost every time, $12.6 \%$ indicated every time and $19.5 \%$ reported never 
Table 1. Characteristics.

\begin{tabular}{|c|c|c|}
\hline Variables & $\mathrm{n}$ & $\%$ \\
\hline \multicolumn{3}{|l|}{ Age } \\
\hline Mean (SD) & $21.45(1.10)$ & \\
\hline Median (Min: Max) & $21(20: 27)$ & \\
\hline $20-22$ & 141 & 88.7 \\
\hline $23-25$ & 15 & 9.4 \\
\hline$<25$ & 3 & 1.9 \\
\hline \multicolumn{3}{|l|}{ Education } \\
\hline Primary school & 11 & 6.9 \\
\hline Secondary school & 118 & 74.2 \\
\hline Bachelor degree and higher & 30 & 18.9 \\
\hline \multicolumn{3}{|l|}{ Income per month (Baht) } \\
\hline$>5000$ & 20 & 12.6 \\
\hline $5000-10,000$ & 128 & 80.5 \\
\hline$<10,000$ & 11 & 6.9 \\
\hline \multicolumn{3}{|l|}{ Alcohol drinking } \\
\hline Everyday & 15 & 9.4 \\
\hline Once a week & 36 & 22.6 \\
\hline Less than once a week & 12 & 7.6 \\
\hline Never & 96 & 60.4 \\
\hline \multicolumn{3}{|l|}{ Drugs (amphetamine) } \\
\hline Yes & 41 & 25.8 \\
\hline No & 118 & 74.2 \\
\hline \multicolumn{3}{|l|}{ Injection of drugs } \\
\hline Yes & 11 & 6.9 \\
\hline No & 148 & 93.1 \\
\hline \multicolumn{3}{|l|}{ Marital status } \\
\hline Yes & 34 & 21.4 \\
\hline No & 125 & 78.6 \\
\hline \multicolumn{3}{|l|}{ Age at marriage } \\
\hline$<=15$ & 7 & 20.6 \\
\hline $16-20$ & 20 & 58.8 \\
\hline$>21$ & 7 & 20.6 \\
\hline Min: $\max$ & $15: 21$ & \\
\hline \multicolumn{3}{|l|}{ Currently living } \\
\hline Married and living with wife & 21 & 13.2 \\
\hline Married and living with other & 4 & 3.5 \\
\hline Married and living with sex partner & 9 & 5.7 \\
\hline Not married but living with sex partner & 54 & 33.9 \\
\hline Not married and living alone & 71 & 44.7 \\
\hline
\end{tabular}


used. The majority of the respondents knew the place or person to obtain the condom from (93.7\%). For sex with men, 15.7\% of the respondents had sex with men. Among those, one-third of them had oral sex activity (36.0\%), 20.0\% had anal sex and nearly a half of them had both oral and anal sex activities, three-fourths of them did not use a condom when having sex with men(76.0\%) and only $16.0 \%$ used a lubricant such as KY jelly, lotion and saliva (Table 2).

\subsection{HIV, STDs History and Knowledge and Attitude}

The majority of the respondent knew about HIV and STDs (88.7\%), more than half of those have been tested for HIV and STDs (59.1\%) and more than two-thirds of them don't know the result, while $20.8 \%$ reported negative results. Moreover, respondents also reported their STDs as follows: gonorrhea of $15.1 \%$, chlamydia of $5.7 \%$, syphilis of $4.4 \%$ and hepatitis B of $3.1 \%$. When their knowledge and attitude of HIV and STDs were asked, more than half of the respondents had a high score of $57.2 \%$ (Table 3 ).

\subsection{Factors Effecting with Condom Use}

Of all the participants, $96.2 \%$ had sexual intercourse during the past 6 months. Among those $41.2 \%$ had used a condom and $58.8 \%$ had not used condom for the last sexual intercourse. The older ages in the conscripts were more likely to use a condom (Adjust $\mathrm{OR}=2.1,95 \% \mathrm{CI}=1.2-9.4$ ) and those with a higher education level (adjust $\mathrm{OR}=8.9,95 \% \mathrm{CI}=1.2-19.1$ ). The participants who frequently drank alcohol, took drugs and had injected drugs used condoms less. The unmarried group used condoms more than the married group $(\mathrm{OR}=1.4,95 \% \mathrm{CI}=$ 0.45 - 3.9) and the participants who had sex with men used condoms less than those who had sex with a woman (Adjusted $\mathrm{OR}=2.2,95 \% \mathrm{CI}=0.3-9.1$ ). Condom use was more significant with those who had tested for HIV and STDs (Adjusted $\mathrm{OR}=1.6,95 \% \mathrm{CI}=0.8-3.9$ ) and had higher knowledge of and [a more aware] attitude towards HIV and STDs (adjusted OR $=1.5,95 \% \mathrm{CI}=0.6$ 2.6) (Table 4).

\section{Discussion}

This study documented condom use among conscripts in Thailand and also factors associated with it. We examined the extent to which characteristics of Thai male youth/conscripts aged $20-27$ years chosen randomly by lottery method to serve in the RTA. The difference, according to the results of the analysis, was understood in terms of different characteristics. The younger male group needs to take appropriate measures from conducive factors specific to individuals and protect themselves from STIs/HIV based on self-assessment of perceiving risk.

This study was conducted overall 159 conscripts who serve in the RTM/RTA. Among those, 96.2\% reported sexual experience and nearly half of the respondents reported use of condom for the last sexual intercourse (44.2\%). This study found that reported sexual intercourse among male military youth indicates a lower rate of frequent condom use (12.6\%) and among this group, while they 
Table 2. Sex experience and condom use.

\begin{tabular}{|c|c|c|}
\hline Variables & $\mathbf{n}$ & $\%$ \\
\hline \multicolumn{3}{|l|}{ Age at the first sex } \\
\hline Mean (SD) & $15.86(1.77)$ & \\
\hline Median (Min: Max) & $16(11: 20)$ & \\
\hline \multicolumn{3}{|l|}{ First sexual intercourse } \\
\hline Female & 144 & 90.6 \\
\hline Male & 15 & 9.4 \\
\hline \multicolumn{3}{|l|}{ Sexual intercourse last 6 months } \\
\hline Female only & 134 & 83.2 \\
\hline Male only & 6 & 4.0 \\
\hline Both male and female & 19 & 14.8 \\
\hline \multicolumn{3}{|l|}{ Sex with women } \\
\hline \multicolumn{3}{|l|}{ Had sex experience } \\
\hline Yes & 153 & 96.2 \\
\hline No & 6 & 3.8 \\
\hline \multicolumn{3}{|l|}{ Number of sex partners past 6 months } \\
\hline $1-5$ & 133 & 86.9 \\
\hline $6-10$ & 12 & 7.9 \\
\hline $11-15$ & 8 & 5.2 \\
\hline Mean (SD), Median (Min: Max) & $1.90(1.71), 1(1: 15)$ & \\
\hline \multicolumn{3}{|c|}{ Condom used in the last sexual intercourse } \\
\hline Yes & 63 & 41.2 \\
\hline No & 90 & 58.8 \\
\hline \multicolumn{3}{|l|}{ Who offered to use condom } \\
\hline Yourself & 41 & 65.1 \\
\hline Partner & 6 & 9.5 \\
\hline Joint decision & 16 & 25.4 \\
\hline \multicolumn{3}{|l|}{ The reason for not using condom } \\
\hline Not available & 32 & 35.6 \\
\hline Too expensive & 4 & 4.4 \\
\hline Partner objected & 16 & 17.9 \\
\hline Didn't like them & 58 & 64.4 \\
\hline Didn't think it was necessary & 27 & 30.0 \\
\hline Didn't think of it & 56 & 62.2 \\
\hline \multicolumn{3}{|l|}{ Frequency of condom use } \\
\hline Every time & 20 & 12.6 \\
\hline Almost every time & 28 & 17.6 \\
\hline Sometimes & 80 & 50.3 \\
\hline Never & 31 & 19.5 \\
\hline
\end{tabular}




\section{Continued}

Know place or person for obtaining condom

Yes

\section{Sex with men}

Yes

No

Sexual intercourse with men $(\mathrm{n}=25)$

Oral sex
Anal sex

Both oral and anal sex

Condom used with men in sexual intercourse $(n=25)$

Yes

Lubricants used $(\mathrm{n}=25)$

$$
\text { Yes }
$$

Type of lubricant used $(\mathrm{n}=4)$

KY

Table 3. HIV and STDs history and knowledge and attitude.

\begin{tabular}{ccc}
\hline Variables & $\mathrm{n}$ & $\%$ \\
\hline Know about HIV and STDs & 141 & 88.7 \\
Yes & 18 & 11.3 \\
Tested for HIV and STDs & & \\
Yes & 94 & 59.1 \\
No & 65 & 40.9 \\
HIV results (self-report) & & \\
Positive & 2 & 1.3 \\
Negative & 33 & 20.8 \\
Don't know & 124 & 77.9 \\
STD results (self-report) & & \\
Gonorrhea & 24 & 15.1 \\
Chlamydia & 9 & 5.7 \\
Syphilis & 7 & 4.4 \\
Hepatitis B & 5 & 3.1 \\
Low & & \\
High & 68 & 42.8 \\
Knowledge and attitude about HIV and STDs & & 57.2 \\
\hline
\end{tabular}


Table 4. Factors associated with condom use.

\begin{tabular}{|c|c|c|c|c|c|c|}
\hline Variables & $\begin{array}{c}\text { Yes } \\
(\mathrm{n}=63)\end{array}$ & $\begin{array}{c}\text { No } \\
(\mathrm{n}=90)\end{array}$ & $\begin{array}{l}\text { Crude } \\
\text { OR }\end{array}$ & $\begin{array}{l}\text { Adjusted } \\
\text { OR }\end{array}$ & $95 \% \mathrm{CI}$ & $p$-value \\
\hline Age & & & & & & 0.01 \\
\hline $20-22$ & $58(42.6)$ & $78(57.4)$ & 1 & & & \\
\hline $23-25$ & $3(21.4)$ & $11(78.6)$ & 1.4 & 1.2 & $0.1-1.0$ & \\
\hline$<25$ & $2(66.7)$ & $1(33.4)$ & 2.7 & 2.1 & $1.2-9.4$ & \\
\hline Education & & & & & & 0.008 \\
\hline Primary school & $3(27.3)$ & $8(72.7)$ & 1 & & & \\
\hline Secondary school & $46(40.4)$ & $68(59.6)$ & 1.8 & 2.9 & $0.5-17.9$ & \\
\hline Bachelor degree and higher & $14(50.0)$ & $14(50.0)$ & 2.6 & 8.9 & $1.2-19.1$ & \\
\hline Alcohol drinking & & & & & & 0.003 \\
\hline Everyday & $6(40.0)$ & $9(60.0)$ & 1 & & & \\
\hline Once a week & $13(37.1)$ & $22(62.9)$ & 0.8 & 0.6 & $0.2-2.5$ & \\
\hline Less than once a week & $6(50.0)$ & $6(50.0)$ & 0.5 & 0.6 & $0.1-3.9$ & \\
\hline Never & $38(41.8)$ & $52(58.2)$ & 0.7 & 0.5 & $0.2-2.4$ & \\
\hline \multicolumn{7}{|l|}{ Amphetamines } \\
\hline Yes & $17(41.5)$ & $24(58.5)$ & 1 & & & 0.019 \\
\hline No & $46(41.1)$ & $66(58.9)$ & 0.9 & 0.8 & $0.3-1.2$ & \\
\hline \multicolumn{7}{|l|}{ Injecting drugs } \\
\hline Yes & $5(50.0)$ & $5(50.0)$ & 1 & & & 0.036 \\
\hline No & $58(40.6)$ & $85(59.4)$ & 0.7 & 0.5 & $0.1-2.3$ & \\
\hline \multicolumn{7}{|l|}{ Married status } \\
\hline Yes & $12(35.3)$ & $22(64.7)$ & 1 & & & 0.03 \\
\hline No & $51(42.9)$ & $68(57.1)$ & 1.4 & 1.2 & $0.5-2.8$ & \\
\hline $\begin{array}{l}\text { Sexual intercourse } \\
\text { last } 6 \text { months }\end{array}$ & & & & & & 0.0014 \\
\hline Female only & $47(35.1)$ & $87(64.9)$ & 1 & & & \\
\hline Male only & $2(33.3)$ & $4(66.7)$ & 1.6 & 2.2 & $0.3-9.1$ & \\
\hline Both male and female & $8(42.1)$ & $11(57.9)$ & 1.2 & 1.7 & $0.5-3.9$ & \\
\hline Tested for HIV and STDs & & & & & & 0.005 \\
\hline Yes & $34(37.8)$ & $56(62.2)$ & 1 & & & \\
\hline No & $29(46.1)$ & $34(53.9)$ & 1.5 & 1.6 & $0.8-3.9$ & \\
\hline $\begin{array}{l}\text { Knowledge of and } \\
\text { attitude to HIV and STDs }\end{array}$ & & & & & & 0.0008 \\
\hline Low & $28(43.1)$ & $37(56.9)$ & 1 & & & \\
\hline High & $35(39.8)$ & $53(60.2)$ & 1.9 & 1.5 & $0.6-2.6$ & \\
\hline
\end{tabular}


sometimes used condoms the levels of use were never high $(50.3 \%$ and 19.5\% respectively). The participants also mention the reasons for not using a condom were that it was not available, they didn't like it, they didn't think of it or they didn't think it was necessary.

Our study found that the youngest of the participants had first sex at a low of 11 years, while previous study has shown at 12 years [19]. The timing of sexual debut also affects the risk of infection with HIV and STDs. One reason why the early onset of sexual activity is a risk factor for acquiring an STI is that the period of potential exposure to infection is longer and previous study also confirmed that the lower the age the lower is HIV and STDs prevention [15]. Furthermore, this study revealed that male youth who were unmarried used condoms less than the married group, a finding also confirmed by the previous study [19]. It can be said that the pattern of condom-use was more critical among the younger people compared to the older ones within the considered age-group of the youths. However, The Ministry of Public Health has many health-education programs, peer-group programs, youth leadership programs, and friend corners program in Thailand [20]. Nowadays, condom-promotion programs should be targeted at the young people, because young people are curious about new experiences, including sexual experience. At the same time, they are also likely to be more apprehensive of HIV/STDs and unwanted pregnancy that affect their lives for the long term [21].

The study also identified education level as one of the major factors to increase the condom use among male youth. The level of education increases response to perception of risk and promotion of condoms and highlights the need for special efforts to reach men with educational attainment. The gap between the highly-educated and the low-educated is significant with condom use. Also, the consumption of alcohol, oral use of drugs and use of injection drugs are factors that impede risk of condom use among the youth/young conscript population. The study of Tunyarak [22] reviewing high HIV infection among people who used drugs, also confirmed that sexual risk behavior under the influence of drugs, injection drugs alcohol drinking was the most probable cause of noncondom use and high prevalence of HIV infection was the major result.

However, our finding on sexual behaviors was that nearly one-fourth of the participants were report having had sex with both female and male $(14.8 \%)$ and this finding is also confirmed by previous studies that this is due to the lack of proper women/appropriate female sex partners. [7] [9]. However, the survey found that some participants had sex with males (4.0\%) and this finding was the same a Chinese study [23] in which Cong reported nearly 3.7\% of Chinese male university students experienced, at least once, same-gender sexual contact. Nevertheless, our finding reported lower than a study of Jianknng Chao who found that $7.5 \%$ of conscripts in Taiwan have had homosexual intercourse [24]. This result demonstrates that homosexual and/or bisexual people are becoming more visible in Thailand, and there is a growing gay liberation movement in there. Another reason is that there is no policy that prohibits homosexual or bisexual 
individuals from serving in the military, so subjects feel free to disclose their sexual history. Meanwhile, the Royal Thai Military has a regulation prohibiting transgender or she-male personnel serving in the Thai Military. Surprisingly, the groups of homosexuals and bi-sexual in this study reported the percentage of condom use of $33.3 \%$ that was lower than previous studies in Thailand in which van Griensven found 65.6\%, Tareerat reported $63.3 \%$ and Mansergh G documented 55.0\%, [10] [18] [25]. While our finding was similar to the study of Cong L's study in China which reported $33.8 \%$ of males in university used condoms [23], this was because the study of homosexuals and bisexuals are limited in Thailand due to the culture context and gathering information from this population is difficult, as being homosexual is taboo in Thai culture and many other societies [22] and is a sensitive issue in the military [1] [2].

This study shows slightly half of the respondents had a high level knowledge of sexual and HIV/STDs issues. Beside this, the statistical analysis also confirmed that the higher knowledge of HIV and STDs significantly affected condom use. Knowledge is the most important factor to achieve a behavioural change. The Government of Thailand has launch a $100 \%$ condom use program, in combination with other prevention efforts, and this has proved very effective in discouraging unprotected intercourse in establishment-based sex work [12] [26]. It now needs to strengthen and increase prevention efforts or specific programs, especially among youth who still exhibit high risk sexual behaviors. The results of this study suggest that an individual's knowledge of risk of STIs/HIV infections has crucial effects on condom use in sexual union/intercourse. Knowledge of risk is to be considered the first stage toward safer behavior. Hence, future sex education programs can enhance their effectiveness by using a mix of mass media and interpersonal communications to repeatedly expose younger people to key campaign messages. In conclusion, the results of the analysis showed that age, education level, alcohol drinking, use of drugs both through injection and amphetamines, married status, testing for HIV/STDs and knowledge were significant factors that affected condom use.

A few limitations of this study should be noted. First, the authors did not run the sampling methods for selecting the study samples, because the conscripts who served in the RTA were randomly selected by lottery method twice a year, so it can be confirmed that the conscripts who join the military have already been randomly selected. Second, a bias introduced by under-reporting is possible as premarital sex is a sensitive issue. And third, the data may be biased because the questionnaire was a self-administered questionnaire with $1.2 \%$ of participants not responding to the survey. However, an attempt was made to minimize this bias by ensuring privacy during the completion of the questionnaire and using the anonymous self-administered survey.

\section{Acknowledgements}

We would like to thank the peer interviewers for their dedication and support, all participants who supported the benefit data and The $3^{\text {rd }}$ Army Area Head- 
quarters, Naresuan Fort, Muang District, Phitsanulok Province, Thailand. This study was partly supported by Naresuan University, Thailand and Shanghai Center for Disease Control \& Prevention (SCDC), P.R. China.

\section{References}

[1] UNAIDS (1998) “AIDS and Military” UNAIDS Point of View.

[2] UNAIDS (2004) HIV/AIDS Prevention and Control: An Experience of the Royal Thai Army in Thailand. WHO Library Cataloguing-in-Publication Data.

[3] Bing, E.G., Bingham, T. and Millett, G.A. (2008) Research Needed to More Effectively Combat HIV among African-American Men Who Have Sex with Men. Journal of the National Medical Association, 100, 52-56.

[4] Szwarcwald, C.L., de Andrade, C.L.T., Pascom, A.R.P., Fazito, E., Pereira, G.F.M. and da Penha, I.T. (2011) HIV-Related Risky Practices among Brazilian Young Men, 2007. Cadernos de Saúde Pública, Rio de Janeiro, 27, S19-S26.

[5] Staton, M., Leukefeld, C., Logan, T.K., Zimmerman, R., Lynam, D., Milich, R., et al. (1999) Risky Sex Behavior and Substance Use among Young Adults. Health \& Social Work, 24, 147-154. https://doi.org/10.1093/hsw/24.2.147

[6] Szwarcwald, C.L., Carvalho, M.F., Barbosa Júnior, A., Barreira, D., Speranza, F.A. and Castilho, E.A. (2005) Temporal Trends of HIV-Related Risk Behavior among Brazilian Military Conscripts, 1997-2002. Clinics, 60, 367-374. https://doi.org/10.1590/S1807-59322005000500004

[7] WHO (2008) Prevention and treatment of HIV and Other Sexually Transmitted Infections among Men Who Have Sex with Men and Transgender Populations: Report of a Technical Consultation, 15-17 September 2008, Geneva.

[8] WHO (2010) HIV/AIDS among Men Who Have Sex with men and Transgender Populations in South-East Asia: The Current Situation and National Responses. New Delhi.

[9] Foreman, M. (2002) Combat AIDS: HIV and the World's Armed Forces. Healthlink Worldwide, London.

[10] Chemnasiri, T., Netwong, T., Visarutratana, S., Varangrat, A., Li, A., Phanuphak, P., Jommaroeng, R., Akarasewi, P. and van Griensven, F. (2010) Inconsistent Condom Use among Young Men Who Have Sex with Men, Male Sex Workers, and Transgenders in Thailand. AIDS Education and Prevention, 22, 100-109. https://doi.org/10.1521/aeap.2010.22.2.100

[11] National AIDS Prevention and Alleviation Committee (2008) National Plan for the Strategic and Integrated HIV and AIDS Prevention Alleviation (2007-2011). Ministry of Public Health, Nonthaburi.

[12] Hanenberg, R.S., Rojanapithayakorn, W., Kunasol, P. and Sokal, D.C. (1994) Impact of Thailand's HIV-Control Programme as Indicated by the Decline of Sexually Transmitted Diseases. The Lancet, 344, 243-245. https://doi.org/10.1016/S0140-6736(94)93004-X

[13] Danyuttapolchai, J., Poolkaysorn, S., Tangrua, W. and Plipat, T. (2007) HIV SeroSurveillance, Thailand 2006 (Round 24) (in Thai). Thai AIDS Journal, 19, 125-140.

[14] van Griensven, F., Thanprasertsuk, S., Jommaroeng, R., Mansergh, G., Naorat, S., Jenkins, R.A., et al. (2005) Evidence of a Previously Undocumented Epidemic of HIV Infection among Men Who Have Sex with Men in Bangkok, Thailand. AIDS, 19, 521-526. https://doi.org/10.1097/01.aids.0000162341.50933.e8

[15] National AIDS Prevention and Alleviation Committee (2010) National Plan for the 
Strategic and Integrated HIV and AIDS Prevention Alleviation (2007-2011). Ministry of Public Health, Nonthaburi.

[16] London, A.S., VanLandingham, M.J. and Grandjean, N. (1997) Socio-Demographic Correlates, HIV/AIDS-Related Cofactors, and Measures of Same-Sex Sexual Behavior among Northern Thai Male Soldiers. Health Transition Review, 7, 33-60.

[17] Kaewmarin, N., Jitsabuy, B., Pimpa, Y. and Plipat, T. (2007) Results of Behavioral Surveillance System among Male Conscripts, Thailand 1995-2004 [in Thai]. Thai AIDS Journal, 19, 155-164.

[18] National AIDS Prevention and Alleviation Committee (2010) UNGASS COUNTRY PROGRESS EPORTTHAILAND Reporting Period January 2008-December 2009.

[19] Haque, M.R. and Soonthorndhada, A. (2009) Risk Perception and Condom-use among Thai Youths: Findings from Kanchanaburi Demographic Surveillance System Site in Thailand. Journal of Health, Population and Nutrition, 27, 772-783.

[20] Fongkaew, W., Fongkaew, K. and Muecke, M. (2006) HIV/Sexual and Reproductive Health Program for HIV Prevention: The Youth-Adult Partnership with School Approach. Journal of the Medical Association of Thailand, 89, 1721-1732.

[21] Murphy, J.J. and Boggess, S. (1998) Increased Condom Use among Teenage Males, 1988-1995: The Role of Attitudes. Family Planning Perspectives, 30, 276-303. https://doi.org/10.2307/2991503

[22] Thaikruea, L. and Seetamanotch, S. (2005) Characteristics and Number of Men Who Have Sex with Men in Phuket, Thailand. Bulletin of Chiang Mai Associated Medical Sciences, 44, 1-7.

[23] Cong, L., Masako, O.K., Xu, G., Ma, Q., Pan, X., Zhang, D., Homma, T. and Kihara, M. (2008) The Characterization of Sexual Behavior in Chinese Male University Students Who Have Sex with Other Men: A Cross-Sectional Study. BMC Public Health, 8, 250. https://doi.org/10.1186/1471-2458-8-250

[24] Chao, J., Lin, Y., Ma, M., et al. (2010) Sexual Knowledge, Attitudes and Activity of Men Conscripted into the Military. BMC Public Health, 10, 577. https://doi.org/10.1186/1471-2458-10-577

[25] Mansergh, G., Jommaroeng, R., Jenkins, R.A., Stall, R., Jeeyapant, S., Phanuphak, P., Tappero, J.W. and van Griensven, F. (2006) Inconsistent Condom Use with Steady and Casual Partners and Associated Factors among Sexually-Active Men Who Have Sex with Men in Bangkok, Thailand. AIDS and Behavior, 10, 743-751. https://doi.org/10.1007/s10461-006-9108-4

[26] Chamratrithirong, A., Thongthai, V., Boonchalaksi, W., Guest, P., Kanchanachitra, C. and Varangrat, A. (1999) The Success of the 100\% Condom Promotion Programme in Thailand: Survey Result of the Evaluation of the $100 \%$ Condom Promotion Programme in Thailand. Institute for Population and Social Research, Mahidol University, Bangkok, 124 p. 
Submit or recommend next manuscript to SCIRP and we will provide best service for you:

Accepting pre-submission inquiries through Email, Facebook, LinkedIn, Twitter, etc. A wide selection of journals (inclusive of 9 subjects, more than 200 journals)

Providing 24-hour high-quality service

User-friendly online submission system

Fair and swift peer-review system

Efficient typesetting and proofreading procedure

Display of the result of downloads and visits, as well as the number of cited articles Maximum dissemination of your research work

Submit your manuscript at: http://papersubmission.scirp.org/

Or contact wja@scirp.org 